\title{
Chinese ideographic writing as a picture of the world: theoretical approach
}

\author{
Daria Domashevskaya ${ }^{* 1}$, Tatiana Shishmareva ${ }^{1}$, and Elena Khamaeva ${ }^{2}$ \\ ${ }^{1}$ Irkutsk State University, 664003 Irkutsk, Russia \\ ${ }^{2}$ MGIMO University, 119454 Moscow, Russia
}

\begin{abstract}
The paper deals with an ideographic writing presented from the standpoint of systems theory, grammatology and semiotics. Ideographic writing is regarded as a natural linguistic semiotic system with its own picture of the world.Ideographic writing as a spacereflects a whole set of writing signs as the ethno-linguistic and cultural reflection of the external physical space of the world and its fixation in the graphic component of the semiosphere as they are perceived by the Chinese ethnic group. Writing as a system focuses on the hierarchical and structural aspects, on establishing its semiographic framework, formation and interpretation models of character components. Ideographic writing as a picture of the world has a semiographic framework that reveals types of knowledge structures that can be seen behind the structure of the characters. The ideographic picture of the world forms a graphic metamodel of Chinese ethno-linguistic semiosphere. Authors propose a graphic metamodel of ideographic writing system based on the semiographic approach. This approach is applied to represent a semiographic framework of the Chinese ideographic writing space, a framework that consists of 540 bushou systematised by Xu Shen in the first Chinese dictionary "Shuo wen jie zi".
\end{abstract}

\section{Introduction}

The development of modern scientific knowledge is currently associated with the emergence of a new paradigm of post-non-classical science - global evolutionism, aimed at initiating a new dialogue between man and nature [15]. This paradigm is characterized by the interconnection of self-organizing systems of different complexity, it exists in terms of interdisciplinarity and has a dialogical character. Its scientific methodology is characterized by a "pluralistic tendency, assertion of the value of various scientific standards" $[4, \quad$ p.53 $]$. "New realities affirm polyfundamentalism, the invers approach, the fundamental openness of systems, the branching graphics of their descriptions, and refute the principles of reductionism, elementarism, linearity" [12, p. 60].

In this paper, we proceed from the fact that any systems consist of many parts interacting with each other in a complex way: a society consisting of people, an organism with its cells, a liquid consisting of molecules, writing consisting of characters. The result of its interactions is a new quality of this system, namely, the effect of self-organization [15].

In Bertalanffy's works the system is defined as "a complex of elements in interaction" [16, p.15]. A. Hall and R. Fagin propose to consider "a set of objects together with relationships between the objects and between their attributes" as a system [1, p.18], emphasizing the importance of interrelationships between the elements of the system that "is said to behave as a whole or coherently" [1, p.20]. Presently, approaches to the system studies cover a number of objects from different fields of knowledge "as sets of interrelated elements acting as a single whole" [2, p.11]. Accordingly, the systematic approach is defined by I. V. Blauberg, V. N. Sadovsky, E. G. Yudin as "an explicit expression of the procedures for representing objects as systems and methods for studying them (descriptions, explanations, predictions, designs, etc.)" [2, p.11].

The purpose of this article is to substantiate the approach to the description of the Chinese ideographic writing from the standpoint of the systems theory. We present a graphic metamodel of Chinese ideographic writing system, which relates to the ideographic picture of the world as a semiographic framework. The latest is regarded as a component of the more compound system - the Chinese language picture of the world.

The relevance of the article is to consider ideographic writing as a variety of natural linguistic semiotic systems each with its own picture of the world. This picture has a distinctive semiographic framework that reveals various types of knowledge structures that can be seen behind the structure of the Chinese characters. And above all the ideographic picture of the world forms the key part of the Chinese ethno-linguistic culture semiosphere - its graphic metamodel.

\footnotetext{
*Corresponding author: domashevskayad@gmail.com
} 


\subsection{Statement of the problem}

The authors propose a three-component approach to the description of ideographic writing: ideographic writing as a space, a system and a picture of the world. These three models are not mutually exclusive, they complement each other to provide a more detailed description of writing as a product of anthropomorphic etiology.

By space in writing we mean space in its broadest philosophical definition as "the fundamental (along with time) concept of human thinking reflecting the multiple nature of the world's existence, its heterogeneity" [10]. At the same time, a multitude of objects existing in human perception simultaneously forms a complex spatial image of the world - a necessary condition for the orientation of any human activity. The space of writing contemplates the semiographic content of the language, percepts a non-verbal, but material representation of things. At the same time the space of writing comprises and formulates the whole experience of mankind not as opposed to an external speech, but additional to it. The space of writing is formally a system, namely, a set of graphic elements which relationships and connections form an integrity, unity.

By writing as a system we understand the same integrity, but with a focus on the hierarchical and structural aspects, on establishing its semiographic framework, formation and interpretation models of character components, identifying the intensional (internal, "writing in and for itself") and the extensional (external, writing as a "necessity", as a component of a larger system, e.g. language system), writing system characteristics (like distinguishing between the intension and extension proposed by R. Karnap) [9].

And finally, the notion of the ideographic picture of the world attracts us by the opportunity to look at the system of ideographic writing as the creation of an unknown demiurge, as a product of the holistic functioning and interaction of all aspects and levels, the opportunity to observe the correlation between the mechanisms of sign formation and the mechanisms of thinking. Also interesting is the prospect of finding out the cognitive mechanisms of man (both his principles of meaning formation and extralinguistic content acquisition) by analyzing grammatologo-semantic relations in writing signs.

Oleg M. Gotlib in The Fundamentals of the Grammatology of Chinese Writing considers ideographic writing as a complex semiotic system with a number of features such as materiality, naturalness, heterogeneity (polymorphism), discreteness (severalty, disintegration) and hierarchy. Materiality consists in the sign and semiotic characteristics of writing, i.e. "the components are not significant by themselves, but serve to designate something outside of them" [8,p.23]. Naturalness of the system of Chinese characters consists in their ability to be reduced to a limited set of the simplest elements - features (graphs), represented by a list. These graphs are not proper characters due to their being meaningless, but they do have signifying functions [8,p.23]. Polymorphism of Chinese writing lies in the ability of its primary elements (features, graphs) to be different in form, while maintaining their identity in nature and function. Moreover, the "polymorphism of simple units serves as the basis for the polymorphism of complex units" [8,p.23]. Their hierarchic character and discreteness are manifested in the multilevel character of Chinese writing signs where, through a set of rules, simpler units make up more complex ones and "all signs of Chinese writing can be divided into smaller units, that is, they are discreet" [8,p.23].

\section{Methods and material}

When considering writing as a self-organizing system of semiotic nature, we relied on the most important concepts of systems theory (L. von Bertalanffy, I.V. Blauberg, V.N. Sadovsky, E.G. Yudin) and on the postulates of synergy approach (I. Prigogine, I. Stengers). Secondly, we took into account the set of rules of generative grammar (N. Chomsky). Thirdly, we paid close attention to the works of researchers of the linguistic picture of the world - from general focus on the role of the human factor in its formation (B. A. Serebrennikov, V. I. Postovalova) to its narrow aspects such as linguistic pictures of the world of the Chinese (T. E. Shishmareva, S.V. Stefanovskaya). The concept of the "semiosphere" by Yu. Lotman formed the framework of our research, and so did the characteristics of the Chinese written signs proposed by O.M. Gotlib.

\section{Results and discussion}

The system approach considers any object as a system an integral complex of interrelated elements (I. V. Blauberg, V. N. Sadovsky, E. G. Yudin); a set of interacting objects (L. von Bertalanffy); complex of entities and relationships (A. D. Hall, R.I. Fagen, the late L. von Bertalanffy) - if its existence meets the principles that are applicable to the ideographic writing.The principles are:

1) Integrity considers the system as a whole and as a subsystem for higher levels. So, writing can be considered introspectively, in and for itself, and as one of the component system of language, speech, culture, etc.

2) Hierarchy of the structure, that is, the presence of many (at least two) elements is based on the subordination of the elements of the lower level to the elements of the highest level. Writing has a hierarchy of graphic elements: from the simplest graphemes and letters, to sentences and texts.

3) Structuring analyzes the elements of the system and their relationships - within a specific organizational structure. The system functions less due to the properties of its elements, but more due to the properties of the structure itself. Thus, writing as a structure can be considered, firstly, as a set of signs - characters (ideographic writing) and letters (phonographic writing); secondly, as the semiographic framework of the written culture. The latest, in turn, cumulates and represents the 
cognitive experience of a human, considering that both experience and human are also systems.

4) Plurality allows us to use multiple models to describe individual elements and the system as a whole. Phenomenologically, writing is a model for description and fixation of many systems, likewise the ability of language to explain a language by means of the language itself. Writing systems' descriptions include diachronic, structural-functional, historical standpoints (I. Friedrich, E. Doblhofer, I. Gelb). At present, there are new models for describing language and writing, for example, biosemiotics represents isomorphism of the genetic code and semiotic systems (R.O. Jacobson, F. Jakob, S.T. Zolyan, R.I. Zhdanov). The theory of fractals is also applicable to the problem of writing signs origin (G. Julia, B. Mandelbrot).

5)Systemic nature lies in the quality of an object to have all the features of the system. Writing is undoubtedly a system: it is complete, hierarchical, structural, open to modeling and description; moreover, it is itself a representative of the models for its description.

We presume the main property of writing as a system is to cumulate cognitive experience of humanity and to hold the value-meaning space of a certain linguistic culture as an open self-organizing system. This approach enables us to conclude that writing, as language itself, cannot be the subject of excluded observation, outside the researcher, since the personal experience of an observer enriches knowledge about it at each stage of study. It forms, according to N. Bohr's complementarity principle, a more consistent picture of the linguoculture system and, broadly, the more consistent picture of the whole cognitive activity of a human being. This approach is a peculiar blend of the subjective and the objective, and it is consonant with the concept of Michael Polanyi's personal knowledge as "active comprehension of cognoscible things, an action requiring particular skill” $[13$, p.18].

\subsection{Ideographic writing as a graphic metamodel of Chinese ethnolinguistic culture}

The factor of the researcher/observer in semiosis plays the key role, since the sign becomes a sign only for the one who is able to discern the meaning in it. A manresearcher in the anthropocentric paradigm is the "measure of all things", all the new possible worlds and semiospheres form around him. Moreover, these worlds and semiospheres are nothing but the product of his own brain activity. "It was the emphasis on the "human factor" that led to the emergence in various sciences of a number of concepts that represent mental, linguistic, logical, philosophical models of the objective world: conceptual picture of the world, the picture of the world, the image of the world, the model of the world, the conceptual system, the individual cognitive system, the language picture of the world and some others" [18].

The end of the 1900s and the beginning of the 2000s, was marked by a surge of interest in the study of pictures of the world, the "global image of objective reality underlying human outlook, i.e. expressing the essential properties of the world in the understanding of man as a result of his spiritual activity" [14, p.21]. Organic human habitat is not limited to the scientific picture of the world using specialized languages, but requires a description of everyday natural language, reflecting everyday experience. Theories of spaces and pictures of the world describe the fundamental dimensions of human existence, explicate the vectors for describing the dynamics and statics of it, constitute its ontology.

Since man signifies objects relevant for his existence in the language the most interesting aspect of research for linguistics is the linguistic picture of the world. Most of the studies of the linguistic picture of the world are currently based on the description of vocabulary and phraseology. Svetlana Stefanovskaya described the sound picture of the Chinese world based on sound immitations of the Chinese language [18], Tatyana Shishmareva's dissertation work reconstructs the language picture of the Chinese world through its representation in the Chinese ethno-thesaurus 尔雅 "Erya" [17].

The graphic representation of the Chinese written sign disconnects with the phonetic shell of the spoken word. It allows us to assume that the space of signs of Chinese ideographic writing forms its own picture of the world - ideographic, supplementalto language and speech pictures of the world.The ideographic picture of the world is being formed on the basis of existing pictures of the world (language, conceptual, scientific, etc.) according to the principle of complementarity by $\mathrm{N}$. Bohr. The ideographic picture of the world introduces an additional element of sign information. The ideographic picture of the world is not opposed to other world pictures but is proposed as an additional one. On the one hand, it serves linguistic, conceptual and other pictures of the world, on the other hand, it forms a result of their functioning. Thus, writing, in the light of the systems theory, can and must be regarded as a system with its own morphology which consists of its own component systems and spaces.

According to the semiographical approach we describe ideographic writing as one of the natural spatial codes. Along with the verbal language, it is included in the semiosphere of the Chinese ethno-linguistic culture. Like the semantic primitives by A. Wezhbitskaya (based on vocabulary), and the deep structures by N. Chomsky (based on grammar), the space of ideographic writing "reflects a certain model of "semantic quarks" or "semantic primitives" that form not only higher order units of this system - logograms - they also reflect, to some extent, the worldview of the Chinese ethnic consciousness " $[8, \mathrm{p} .40]$. It allows us to single out $a$ semiographical framework of Chinese ideographic writing which, according to us, is represented by 540 bushow (部首) of the first dictionary of characters “ Shuo wen jiezi” (说文解字) (1st century BD - 1st century AD) compiled by $\mathrm{Xu}$ Shen (许慎). As well as a concept of "deep structure" evolved into the area of semantics, 540 basic characters cannot be considered only graphically. It requires grammatical-semantic comprehension, as well as the reconstruction of 
etymography (etymological graphics) to complement the bushou dictionary (written in Zhuanzi 管字 type of writing) by evolutionary earlier versions (periods of Jiaguwen 甲骨文 and Jinwen 金文) [20].

\section{Conclusion}

The theory of systems, grammatological and semiotic approaches allow us to look at the object of study - in the broadest terms, is writing in and for itself, and more specifically, ideographic writing - from the polyparadigmatic point of view. Polyparadigmaticity implies representation of ideographic writing as a phenomenon by means of various paradigms of scientific knowledge that are not related to each other, but their combination helps to reveal some new aspects of functioning of this product of an anthropomorphic etiology, such as writing.

Speaking of ideographic writing as a space, we think of a whole set of writing signs as a variant of the ethnolinguistic and cultural reflection of the external physical space of the world and its fixation in the graphic component of the semiosphere as they are perceived by the Chinese ethnic group. The space of ideographic writing contains a graphic metamodel of the Chinese ethno-linguistic culture. Further study on that point will allow us to gain experience other than the study of vocabulary or grammar of a language but to reveal modeling mechanisms in transition from deep knowledge structures. We consider these structures as a graphic representation of human experience complementary to superficial structures of the Chinese written signs.

Authors regard the system of ideographic writing as a system supplementary to the national language, as one of the heterogeneous natural sign systems (semiotics). Through its basic components' internal organization (morphograms and logograms) a researcher can model the processes of a person's cognitive activity.

We regard ideographic writing as a natural linguistic semiotic system with its own picture of the world that has a distinctive semiographical framework. The ideographic picture of the world dictates various types of knowledge structures that are viewed behind the structure of ideographic signs. It also forms the graphic model of the semiosphere of the Chinese ethno-linguistic culture.

The combination of all possible linguistic semiotic systems forms the larger semiosphere according to the principle of inclusion. At the same time, the whole universe of linguoculture, its "organism", its selforganization and the naturalness of the processes are isomorphic to other open non-linear systems. Thus, writing is always a symbiosis that results in "a delightfully illogical, but exciting and constantly changing chaos and at the same time, a harmonious complete whole" [6,p.32].

\section{References}

1. Arthur, D. Hall, Robert, E. Fagen. Definition of System General Systems, 1, 18-28 (1956)

2. V. Blauberg, V. N. Sadovsky, E. G. YudinSystem approach in contemporary science Methodological problems in systems research,7-48 (1969)

3. L. von BertalanffyGeneralSystem Theory - A critical review General Systems, 7, 1-20 (1962)

4. E.N. BogdanovaResearch methodology of non-linear processes in compound systems Caucasus' scientific view, 1, 52-55, (2010)

5. L.V. ChertovSign prism. About general and special semiotics,320 (2014)

6. E. Doblhofer, I. Friedrich History of Writing: evolution from Ancient Egypt till present days, 400 (2002)

7. D.M. Domashevskaya Communicative space of writing: phonography vs. ideography International Scientific and Practical Conference "Gotlieb's Readings: Asia-Pacific in the Context of Global Development", 95-107 (2017)

8. O.M. Gotlieb Fundamentals of Chinese grammatology (2007).

9. R. Karnap Significance and necessity. Research on semantics and modal logics, (1959)

10. I.T. Kasavin Space Philosophy: Encyclopedic dictionary (2004) https://dic.academic.ru/dic.nsf/enc_philosophy/994/П POCTPAHCTBO / (date of access: 29 September 2018)

11. A.F. KondrashevskySigns of the original categories of Chinese writing and the system of keys "Shuo wen" (1982)

12. T.G. LeshkevichPost-non-classical methodology: the evolution of the paradigm of fundamental philosophy Moscow University Bulletin, Philosophy, 6, 52-70 (1998)

13. M. Polanyi Personal Knowledge: Towards a postcritical philosophy (1985)

14. V.I. PostovalovaPicture of the world in human life/ Human factor's role in the language. Language picture of the world, 8-69 (1988)

15. I. Prigogine, I. Stengers Order Out of Chaos: Man's New Dialogue with Nature, (1986)

16. B.A. Serebrennikov General linguistics. The internal structure of the language, (1972)

17. T.E. Shishmareva The experience of the reconstruction of the linguistic picture of the world on the basis of an ancient lexicographic source, (2008), http://www.dissercat.com/content/opytrekonstruktsii-yazykovoi-kartiny-mira-na-osnovedrevnego-leksikograficheskogoistochnik\#ixzz5TA4ZNoys

18. S.V. Stefanovskaya Sound picture of the world ISLU Bulletin, 117-121, (2009), https://cyberleninka.ru/article/n/zvukovaya-kartina$\underline{\text { mira }}$ 
19. T.P. Zadoenko, Huang Shuying The beginner's course of the Chinese language. Part 1 (2014)

20. T.E. Shishmareva, E.A. Khamaeva, N.V. Terekhova, D.M. Domashevskaya Etymologic dictionary of the basic Chinese characters, 669 (2019) 